\title{
Genomic copy number gains of ErbB family members predict poor clinical outcomes in glioma patients
}

\author{
Rui Liu ${ }^{1,2}$, Yiping Qu ${ }^{1}$, Lihong Chen ${ }^{3}$, Jun Pu${ }^{1}$, Sharui Ma ${ }^{1}$, Xiaozhi Zhang ${ }^{2}$, Qi Yang ${ }^{1}$, \\ Bingyin Shi ${ }^{1,4}$, Peng Hou ${ }^{1,4}$ and Meiju $\mathrm{Ji}^{5}$ \\ ${ }^{1}$ Department of Endocrinology, The First Affiliated Hospital of Xi'an Jiaotong University School of Medicine, Xi'an 710061, \\ P. R. China \\ ${ }^{2}$ Department of Radio-Oncology, The First Affiliated Hospital of Xi'an Jiaotong University School of Medicine, Xi'an 710061, \\ P. R. China \\ ${ }^{3}$ Department of Critical Care Medicine, The First Affiliated Hospital of Xi'an Jiaotong University, Xi'an 710061, P. R. China \\ ${ }^{4}$ Key Laboratory for Tumor Precision Medicine of Shaanxi Province, The First Affiliated Hospital of Xi'an Jiaotong University, \\ Xi'an 710061, P. R. China \\ ${ }^{5}$ Center for Translational Medicine, The First Affiliated Hospital of Xi'an Jiaotong University, Xi'an 710061, P.R. China \\ Correspondence to: Meiju Ji, email: mjji0409@163.com \\ Peng Hou, email: phou@xjtu.edu.cn \\ Keywords: glioma, ErbB family, copy number gain, clinical outcomes \\ Received: April 05, $2017 \quad$ Accepted: August 17, $2017 \quad$ Published: September 23, 2017 \\ Copyright: Liu et al. This is an open-access article distributed under the terms of the Creative Commons Attribution License 3.0 \\ (CC BY 3.0), which permits unrestricted use, distribution, and reproduction in any medium, provided the original author and source \\ are credited.
}

\section{ABSTRACT}

The aim of this study was to investigate copy number of ErbB family members (including EGFR, HER2, HER3 and HER4) in a cohort of gliomas and benign meningiomas (control subjects), and explore the associations of their copy number with clinicopathological characteristics and clinical outcomes of glioma patients. Using real-time quantitative PCR assay, we demonstrated that copy number of EGFR, HER2, HER3 and HER4 in glioma patients was significantly increased compared to control subjects. Moreover, our data also showed that the risk of cancer-related death was positively associated with copy number gain (CNG) of EGFR, HER3 and HER4, but not HER2. CNG of EGFR and HER2 was positively related to radiotherapy, while CNG of HER3 and HER4 was negatively related to chemotherapy. Importantly, EGFR CNG significantly shortened median survival times of glioma patients regardless of gender, tumor grade and therapeutic regimens. Stratified analysis showed that CNG of HER24 almost did not influence the survival of male patients, patients with high-grade tumors and patients receiving chemotherapy, but dramatically shortened median survival times of female patients, those with low-grade tumors and those receiving radiotherapy. Collectively, our data not only demonstrate that the members of ErbB family are frequently amplified in gliomas, but also suggest that these common genetic events may be prognostic factors for poor clinical outcomes in glioma patients.

\section{INTRODUCTION}

Gliomas, also named as gliocytoma, are the most common primary brain tumors in the central nervous system (CNS). It accounts for about $80 \%$ of all brain tumors, with an incidence rate of approximately 7 per
100,000 worldwide [1]. The patients with gliomas may have several neurological symptoms such as headaches, seizures, memory loss, vomiting and visual changes [2]. Despite the existence of various treatments, including surgery, chemotherapy or radiotherapy, its prognosis is still poor $[3,4]$. Therefore, determining the genetic alterations of classic oncogenes will improve the accuracy of clinical 
interpretations and the effectiveness of therapeutics for this cancer.

Tumors are thought to originate from a single clonal state that then expands clonally, accompanied by genetic events that give rise to functional differences, resulting in different stages and characteristics of neoplastic development [5]. Copy number variation $(\mathrm{CNV})$ is increasingly linked to the genetic and phenotypic diversity among cancers, and is frequently associated with the activation of oncogenic drivers or the deletion of tumor suppressors [6-8]. Like other malignancies, the current studies have shed light on molecular events of oncogenes and tumor suppressor genes in gliomas due to numerical chromosomal abnormalities such as genomic gains and losses $[9,10]$.

Growth factors mediate diverse biologic responses including cell proliferation, migration, differentiation and survival by binding to and activating cell-surface receptors with receptor tyrosine kinases (RTKs) activity $[11,12]$. Epidermal growth factor (EGF), one of the first growth factors, was discovered in the early 1960s. EGFs were shown high affinity to bind with its specific receptor EGFR [13]. The EGFR receptor tyrosine kinases family consists of ErbB1 (also known as EGFR or HER1), ErbB2/HER2, ErbB3/HER3 and ErbB4/HER4 [14]. Genomic alterations such as copy number gain (CNG) in members of ErbB family generally lead to their activation, thereby stimulating downstream intracellular signaling pathways, including the RAS/RAF/MEK/ERK (MAPK/ERK), PI3K/AKT, and JAK/STAT pathways, which promote cell proliferation, survival and migration [15]. Given that aberrant activation of ErbB receptors is frequently observed in multiple types of cancer, clinical applications have rapidly emerged around attempts to therapeutically inhibit the function of ErbB receptors in different cancers including monoclonal antibodies (mAbs), small-molecule TKIs and other agents like peptides, affibodies, nanobodies, etc [16, 17]. However, the prognostic significance of CNG of members of ErbB family in gliomas remains largely unclear.

In this study, we investigated copy number of members of ErbB family by using quantitative PCR (qPCR) approach in a cohort of gliomas and control subjects, and explored the association of CNG of members of ErbB family with clinical outcomes of glioma patients.

\section{RESULTS}

\section{Frequent CNG of members of ErbB family in glioma patients}

Copy number of ErbB family members was examined in a cohort of 127 gliomas and 16 benign meningiomas as control subjects using qPCR approach. As shown in Figure 1A and Supplementary Table 1, glioma patients exhibited a significantly higher copy number of
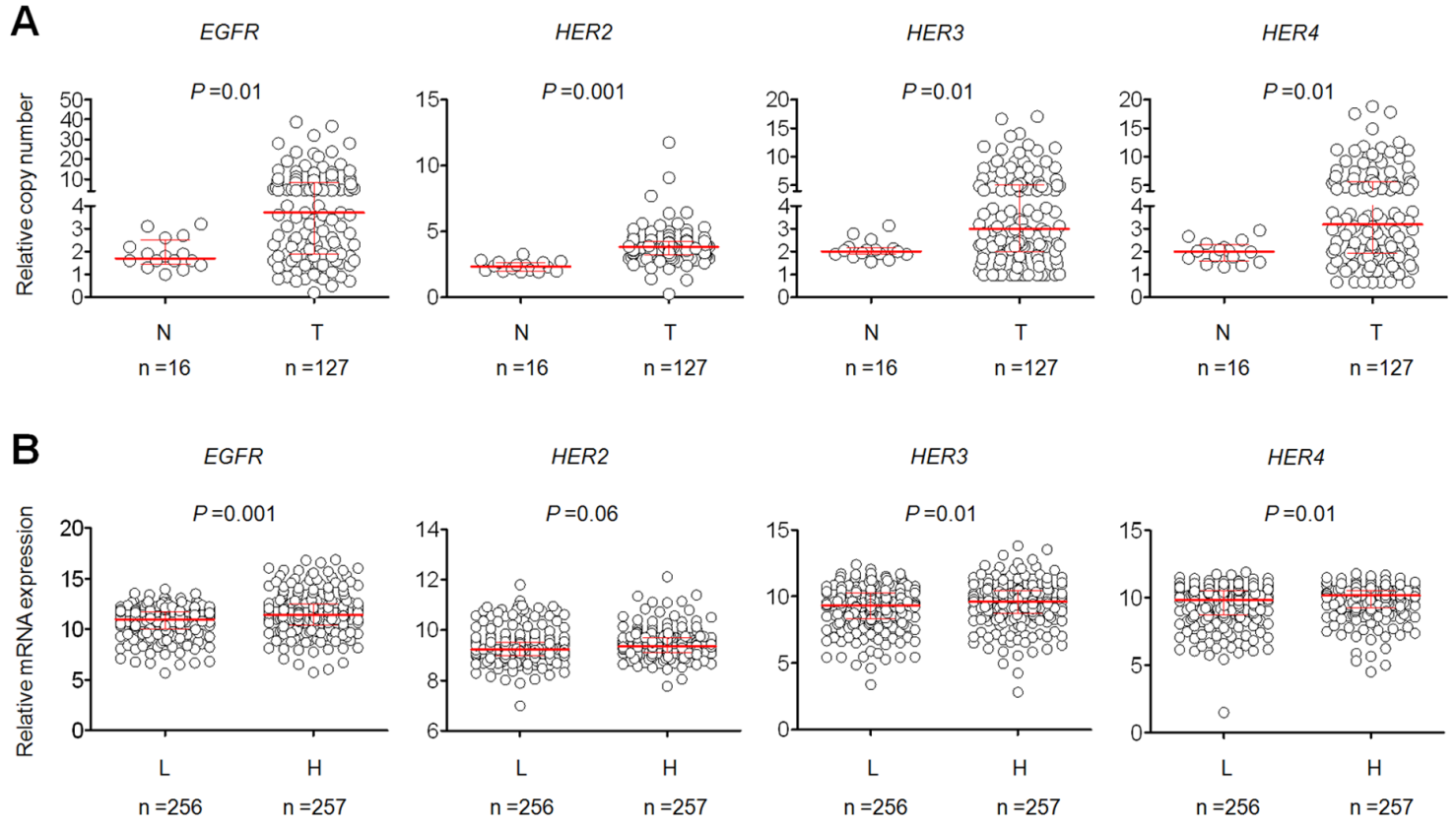

Figure 1: Copy number of members of ErbB family in a cohort of gliomas and control subjects. (A) Copy number of EGFR, HER2, HER 3 and HER4 of each case was determined by a qPCR assay. Each circle represents copy number of the indicated gene of an individual case. Horizontal lines indicate median and interquartile range. T: tumor tissues; N: control subjects. (B) The relationship between copy number of the indicated gene and its mRNA expression in low-grade gliomas from The Cancer Genome Atlas (TCGA) dataset. Horizontal lines indicate median and interquartile range. " $\mathrm{L}$ " and " $\mathrm{H}$ " represent low- and high-copy number of the indicated gene, respectively. A median copy number of each indicated gene is used as cut-off value. 
EGFR (6.53 vs. 1.91; $P=0.01), H E R 2$ (3.87 vs. 2.36; $P$ $=0.001), H E R 3$ (4.21 vs. 2.09; $P=0.01)$, and HER4 (4.43 vs. $1.98 ; P=0.01)$ than control subjects. When a copy number of $\geq 4$ of the indicated genes was considered as $\mathrm{CNG}$ (or gene amplification), we found that $E G F R \mathrm{CNG}$ in $62 / 127(48.8 \%)$ gliomas, HER2 in $44 / 127(34.6 \%)$ gliomas, HER3 in 47/127 (37.0\%) gliomas, and HER4 in 50/127 (39.4\%) gliomas, whereas none was found in control subjects (Table 1). Also shown in Table 1, IDH1 mutations were found in 45 of 127 (35.4\%) patients. Given that genomic alterations are different among the subgroups of glioma, we further compared copy number of ErbB family members according to tumor grade. As shown in Supplementary Figure 1, copy number of EGFR and HER2 was not different between low-grade gliomas (LGGs) and high-grade gliomas (GBMs); however, copy number of HER3 and HER4 was significantly increased in LGGs as compared to GBMs. In addition, two or more amplification events were found in 57 of 127 (44\%) patients (Supplementary Figure 2). To test the association of copy number of the above genes and their mRNA levels, we analyzed the corresponding data in a total of 513 lowgrade gliomas using The Cancer Genome Atlas (TCGA) dataset from the Cancer Browser database (https:// genome-cancer.soe.ucsc.edu). We divided these cases into low- and high-copy groups by using median copy number of each gene. As shown in Figure 1B, the mRNA levels of these four genes in high-copy group were higher than lowcopy group, especially in $\operatorname{EGFR}(P<0.001)$.

\section{Association of CNG of members of ErbB family with clinicopathological features in glioma patients}

Given frequent $\mathrm{CNG}$ of ErbB family members in gliomas, the associations of their $\mathrm{CNG}$ with clinicopathological features of glioma patients were then investigated in a cohort of glioma patients. When copy number of $\geq 4$ was defined as $\mathrm{CNG}$, the glioma patients were subsequently categorized into CNG- and non-CNGgroups of the indicate genes. As shown in Table 2, by using univariate regression analysis, we found that the risk of cancer-related death was significantly increased by the presence of $E G F R$ CNG $(\mathrm{OR}=4.14,95 \% \mathrm{CI}=1.94-8.86$, $P<0.001)$, HER3 CNG $(\mathrm{OR}=2.48,95 \% \mathrm{CI}=1.15-5.40$, $P=0.02)$ and HER4 CNG (OR $=2.16,95 \% \mathrm{CI}=1.02-$ 4.58, $P=0.04)$. The patients with $E G F R \mathrm{CNG}$ had a much higher risk of tumor recurrence $(\mathrm{OR}=3.01,95 \% \mathrm{CI}=1.26$ 7.21, $P=0.01)$. HER 2 was more likely to be amplified in young patients $(\mathrm{OR}=0.61,95 \% \mathrm{CI}=0.40-0.93, P=0.02)$. Notably, HER3 and HER4 CNG were significantly negatively associated with tumor grade (the former: OR $=0.61,95 \% \mathrm{CI}=0.39-0.95, P=0.03$; the latter: $\mathrm{OR}=0.66$, $95 \% \mathrm{CI}=0.40-0.95, P=0.03)$. Increasing evidences have demonstrated that $I D H 1$ mutations are important genetic events, and closely associated with survival benefit in gliomas $[18,19]$. Our data showed that the association of low copy number of EGFR with IDH1 mutations (Table $2)$. In addition, we did not find significant correlations between $\mathrm{CNG}$ of members of ErbB family and other clinicopathological characteristics such as gender, KPS score, radiotherapy, chemotherapy, smoking, drinking and epilepsy (Table 2).

Next, multivariable regression analysis was conducted to assess the independent associations of $\mathrm{CNG}$ of the above genes with tumor grade, recurrence, radiotherapy, chemotherapy and survival status in glioma patients. Similar to the findings from univariate analysis, CNG of EGFR (OR $=9.61,95 \% \mathrm{CI}=2.83-32.7, P<0.001)$, HER3 (OR $=4.47,95 \% \mathrm{CI}=1.35-14.75, P=0.01)$ and HER4 $(\mathrm{OR}=5.07,95 \% \mathrm{CI}=1.50-17.06, P=0.009)$ was still significantly associated with cancer-related death in glioma patients (Table 3). Also shown in Table 3, EGFR $(\mathrm{OR}=0.56,95 \% \mathrm{CI}=0.33-0.94, P=0.03)$, HER3 (OR $=0.42,95 \% \mathrm{CI}=0.24-0.72, P=0.002)$ and HER4 (OR $=0.42,95 \% \mathrm{CI}=0.24-0.73, P=0.002)$ genes were more likely to be amplified in the patients with low-grade tumors as compared to those with high-grade tumors, suggesting that CNG of EGFR, HER3 and HER4 may be early-stage genetic events in glioma tumorigenesis. Notably, we found that $\mathrm{CNG}$ of EGFR (OR $=2.72,95 \%$ $\mathrm{CI}=1.12-6.64, P=0.03)$ and HER2 (OR $=2.42,95 \% \mathrm{CI}$ $=1.03-5.73, P=0.04$ ) was more likely to be found in the patients receiving postoperative radiotherapy, whereas CNG of HER3 (OR $=0.39,95 \% \mathrm{CI}=0.16-0.95, P=0.04)$ and HER4 $(\mathrm{OR}=0.28,95 \% \mathrm{CI}=0.11-0.68, P=0.005)$ was more likely to be found in the patients who did not receive postoperative chemotherapy (Table 3).

We further divided the patients into two groups according to gender. As shown in Supplementary Table 2, CNG of EGFR, HER 2 and HER3 was positively associated with tumor recurrence, especially $E G F R$ in female patients. Moreover, we also found that $\mathrm{CNG}$ of $E G F R$, HER 2, HER 3 and HER4 was correlated with the risk of cancer-related death in female patients (Supplementary Table 2). In male patients, our data showed that HER4 was more likely to be amplified in early-stage tumors. $\mathrm{CNG}$ of HER3 and HER4 was more likely to be found in the patients who did not receive postoperative chemotherapy, while EGFR CNG was more likely to be amplified in the patients receiving radiotherapy (Supplementary Table 3). As expected, we also found that EGFR CNG was significantly associated with increased risk of male patients (Supplementary Table 3). Next, multivariable regression analysis demonstrated that $E G F R \mathrm{CNG}$ in female patients and $\mathrm{CNG}$ of HER3 and HER4 in male patients were still negatively associated with tumor grade (Supplementary Tables 4 and 5). In addition, we also found that EGFR CNG in both female and male patients and CNG of HER3 and HER4 in male patients were closely associated with increased risk of cancer-related death (Supplementary Tables 4 and 5). Also shown in Supplementary Table 
Table 1: Clinicopathological characteristics of glioma patients

\begin{tabular}{|c|c|c|c|c|c|c|}
\hline Characteristics & $\begin{array}{c}\text { No. of } \\
\text { patients (\%) }\end{array}$ & $\begin{array}{c}\text { No. of } E G F R \\
\text { CNG }(\%)\end{array}$ & $\begin{array}{c}\text { No. of } H E R 2 \\
\text { CNG }(\%)\end{array}$ & $\begin{array}{c}\text { No. of } H E R 3 \\
\text { CNG }(\%)\end{array}$ & $\begin{array}{c}\text { No. of } H E R 4 \\
\text { CNG (\%) }\end{array}$ & $\begin{array}{c}\text { No. of } I D H I \\
\text { mutations (\%) }\end{array}$ \\
\hline \multicolumn{7}{|l|}{ Gender } \\
\hline Male & $69(54.3)$ & $32(46.4)$ & $22(31.9)$ & $28(40.6)$ & $28(40.6)$ & $24(34.8)$ \\
\hline Female & $58(45.7)$ & $30(51.7)$ & $22(37.9)$ & $19(32.8)$ & $22(37.9)$ & $21(36.2)$ \\
\hline \multicolumn{7}{|l|}{ Age, years } \\
\hline Mean & 45.1 & $\mathrm{n} / \mathrm{a}$ & $\mathrm{n} / \mathrm{a}$ & $\mathrm{n} / \mathrm{a}$ & $\mathrm{n} / \mathrm{a}$ & $\mathrm{n} / \mathrm{a}$ \\
\hline SD & 16.7 & $\mathrm{n} / \mathrm{a}$ & $\mathrm{n} / \mathrm{a}$ & $\mathrm{n} / \mathrm{a}$ & $\mathrm{n} / \mathrm{a}$ & $\mathrm{n} / \mathrm{a}$ \\
\hline \multicolumn{7}{|l|}{ WHO grade } \\
\hline I & $17(13.4)$ & $11(64.7)$ & $5(29.4)$ & $10(58.8)$ & $10(58.8)$ & $4(23.5)$ \\
\hline II & $61(48.0)$ & $28(45.9)$ & $24(39.3)$ & $23(37.7)$ & $24(39.3)$ & $29(47.5)$ \\
\hline III & $34(26.8)$ & $16(47.1)$ & $7(20.6)$ & $11(32.4)$ & $14(41.2)$ & $11(32.4)$ \\
\hline IV & $15(11.8)$ & $7(46.7)$ & $8(53.3)$ & $3(20.0)$ & $2(13.3)$ & $1(6.7)$ \\
\hline \multicolumn{7}{|l|}{ KPS score } \\
\hline$\leq 80$ & $51(40.2)$ & $25(49.0)$ & $22(43.1)$ & $18(35.3)$ & $18(35.3)$ & $17(33.3)$ \\
\hline$>80$ & $76(59.8)$ & $37(48.7)$ & $22(28.9)$ & $29(38.2)$ & $32(42.1)$ & $28(36.8)$ \\
\hline \multicolumn{7}{|l|}{ Recurrence } \\
\hline No & $31(24.4)$ & $9(29.0)$ & $9(29.0)$ & $7(22.6)$ & $9(29.0)$ & $14(45.2)$ \\
\hline Yes & $96(75.6)$ & $53(55.2)$ & $35(36.5)$ & $40(41.7)$ & $41(42.7)$ & $31(32.3)$ \\
\hline \multicolumn{7}{|l|}{ Radiotherapy } \\
\hline No & $48(37.8)$ & $20(41.7)$ & $12(25.0)$ & $15(31.2)$ & $16(33.3)$ & $14(29.2)$ \\
\hline Yes & $79(62.2)$ & $42(53.2)$ & $32(40.5)$ & $32(40.5)$ & $34(43.0)$ & $31(39.2)$ \\
\hline \multicolumn{7}{|l|}{ Chemotherapy } \\
\hline No & $76(59.8)$ & $39(51.3)$ & $26(34.2)$ & $31(40.8)$ & $35(46.1)$ & $26(34.2)$ \\
\hline Yes & $51(40.2)$ & $23(45.1)$ & $18(35.3)$ & $16(31.4)$ & $15(29.4)$ & $19(37.3)$ \\
\hline \multicolumn{7}{|l|}{ Survival status } \\
\hline Dead & $75(59.1)$ & $47(62.7)$ & $28(37.3)$ & $34(45.3)$ & $35(46.7)$ & $16(21.3)$ \\
\hline Alive & $52(40.9)$ & $15(28.8)$ & $16(30.8)$ & $13(25.0)$ & $15(28.8)$ & $29(55.8)$ \\
\hline \multicolumn{7}{|l|}{ Smoking } \\
\hline No & $92(72.4)$ & $44(47.8)$ & $36(39.1)$ & $30(32.6)$ & $34(37.0)$ & $33(35.9)$ \\
\hline Yes & $35(27.6)$ & $18(51.4)$ & $8(22.9)$ & 17 (48.6) & $16(45.7)$ & $12(34.3)$ \\
\hline \multicolumn{7}{|l|}{ Drinking } \\
\hline No & $121(95.3)$ & $61(50.4)$ & $43(35.5)$ & $45(37.2)$ & $49(40.5)$ & $43(35.5)$ \\
\hline Yes & $6(4.7)$ & $1(16.7)$ & $1(16.7)$ & $2(33.3)$ & $1(16.7)$ & $2(33.3)$ \\
\hline \multicolumn{7}{|l|}{ Epilepsy } \\
\hline No & $70(55.1)$ & $38(54.3)$ & $26(37.1)$ & $28(40.0)$ & $28(40.0)$ & $13.8(18.6)$ \\
\hline Yes & $57(44.9)$ & $24(42.1)$ & $18(31.6)$ & $19(33.3)$ & $22(38.6)$ & $32(56.1)$ \\
\hline
\end{tabular}


Table 2: CNG of members of ErbB family in gliomas: univariate associations with clinicopathological characteristics

\begin{tabular}{|c|c|c|c|c|c|c|c|c|}
\hline \multirow{2}{*}{ Characteristics } & \multicolumn{2}{|c|}{ EGFR CNG } & \multicolumn{2}{|l|}{ HER2 CNG } & \multicolumn{2}{|c|}{ HER3 CNG } & \multicolumn{2}{|c|}{ HER4 CNG } \\
\hline & OR $^{*}(95 \% \mathrm{CI})$ & $P$ & OR* (95\% CI) & $P$ & OR $^{*}(95 \%$ CI $)$ & $P$ & OR $^{*}(95 \%$ CI $)$ & $P$ \\
\hline Gender & $1.24(0.62-2.49)$ & 0.59 & $1.31(0.63-2.72)$ & 0.48 & $0.71(0.34-1.48)$ & 0.36 & $0.90(0.44-1.83)$ & 0.76 \\
\hline $\mathrm{Age}^{1}$ & $1.27(0.86-1.88)$ & 0.23 & $0.61(0.40-0.93)$ & 0.02 & $0.95(0.63-1.41)$ & 0.79 & $0.98(0.66-1.46)$ & 0.93 \\
\hline WHO grade ${ }^{2}$ & $0.84(0.56-1.27)$ & 0.42 & $1.08(0.71-1.66)$ & 0.71 & $0.61(0.39-0.95)$ & 0.03 & $0.66(0.40-0.95)$ & 0.03 \\
\hline KPS score ${ }^{3}$ & $0.98(0.49-2.00)$ & 0.97 & $0.54(0.26-1.13)$ & 0.10 & $1.13(0.54-2.37)$ & 0.74 & $1.33(0.64-2.78)$ & 0.44 \\
\hline Recurrence & $3.01(1.26-7.21)$ & 0.01 & $1.40(0.58-3.38)$ & 0.45 & $2.45(0.96-6.24)$ & 0.06 & $1.82(0.76-4.37)$ & 0.16 \\
\hline Radiotherapy & $1.59(0.77-3.28)$ & 0.21 & $2.04(0.92-4.51)$ & 0.08 & $1.50(0.70-3.20)$ & 0.30 & $1.51(0.72-3.19)$ & 0.28 \\
\hline Chemotherapy & $0.78(0.38-1.59)$ & 0.49 & $1.05(0.49-2.20)$ & 0.90 & $0.66(0.31-1.40)$ & 0.28 & $0.48(0.23-1.03)$ & 0.06 \\
\hline Survival status ${ }^{4}$ & $4.14(1.94-8.86)$ & $<0.001$ & $1.34(0.63-2.84)$ & 0.45 & $2.48(1.15-5.40)$ & 0.02 & $2.16(1.02-4.58)$ & 0.04 \\
\hline Smoking & $1.16(0.53-2.52)$ & 0.72 & $0.46(0.19-$ & 0.08 & $1.95(0.88-4.32)$ & 0.10 & $1.44(0.65-3.16)$ & 0.37 \\
\hline Drinking & $0.20(0.02-1.71)$ & 0.14 & $0.36(0.04-3.20)$ & 0.36 & $0.84(0.15-4.80)$ & 0.85 & $0.29(0.03-2.59)$ & 0.27 \\
\hline Epilepsy & $0.61(0.30-1.24)$ & 0.17 & $0.78(0.37-1.64)$ & 0.51 & $0.75(0.36-1.56)$ & 0.44 & $0.94(0.46-1.93)$ & 0.87 \\
\hline IDH1 mutations & $0.32(0.15-0.69)$ & 0.004 & $1.06(0.49-2.28)$ & 0.87 & $0.78(0.37-1.67)$ & 0.53 & $0.90(0.43-1.90)$ & 0.79 \\
\hline
\end{tabular}

${ }^{*}$ OR: odds ratio with $95 \%$ confidence interval; ${ }^{1}$ Age (per 20 years); ${ }^{2} \mathrm{WHO}$ grade (I, II, III and IV); ${ }^{3} \mathrm{KPS}(>80 ; \leq 80)$; ${ }^{4}$ Survival status (alive $v s$. dead). The cases $<4$ copies were used as reference.

Table 3: CNG of members of ErbB family in gliomas: multivariate models assessing WHO grade, recurrence, radiotherapy, chemotherapy and survival status

\begin{tabular}{|c|c|c|c|c|c|c|c|c|}
\hline \multirow{2}{*}{ Characteristics } & \multicolumn{2}{|c|}{ EGFR CNG } & \multicolumn{2}{|l|}{ HER2 CNG } & \multicolumn{2}{|l|}{ HER3 CNG } & \multicolumn{2}{|l|}{ HER4 CNG } \\
\hline & $\mathrm{OR}^{*}(95 \% \mathrm{CI})$ & $P$ & OR $^{*}(95 \%$ CI $)$ & $P$ & OR $^{*}(95 \% \mathrm{CI})$ & $P$ & OR $^{*}(95 \%$ CI) & $P$ \\
\hline WHC & 0.56 & 0.03 & 4) & 0.42 & 2) & 0.002 & 73) & 0.002 \\
\hline Recurrence & $0.99(0.28-3.58)$ & 0.99 & $1.01(0.30-3.46)$ & 0.98 & $1.14(0.52-2.52)$ & 0.74 & $1.19(0.32-4.38)$ & 0.80 \\
\hline Radiotherapy & $2.72(1.12-6.64)$ & 0.03 & $2.42(1.03-5.73)$ & 0.04 & $1.89(0.77-4.64)$ & 0.16 & $2.10(0.86-5.13)$ & 0.10 \\
\hline Chemotherapy & $0.44(0.19-1.05)$ & 0.07 & $0.87(0.40-1.93)$ & 0.74 & $0.39(0.16-0.95)$ & 0.04 & $0.28(0.11-0.68)$ & 0.005 \\
\hline Survival status ${ }^{2}$ & $9.61(2.83-32.7)$ & $<0.001$ & $1.56(0.53-4.64)$ & 0.42 & $4.47(1.35-14.75)$ & 0.01 & 17.06) & 0.009 \\
\hline
\end{tabular}

"OR: odds ratio with $95 \%$ confidence interval (CI); ${ }^{1}$ WHO grade (I, II, III and IV); ${ }^{2}$ Survival status (alive $v s$. dead). The cases $<4$ copies were used as reference.

5, our data indicated that CNG of HER2-4 was more frequently found in male patients receiving postoperative radiotherapy. In contrast, $\mathrm{CNG}$ of $H E R 3$ and HER4 was more frequently observed in male patients who did not receive postoperative chemotherapy. However, clinical significance and exact mechanism responsible for these associations remain be further elucidated.

\section{Association of CNG of members of ErbB family with poor patient survival}

Univariate survival analysis was conducted to assess the potential associations of CNG of members of ErbB family with patient survival. As shown in Table 4, EGFR
$\mathrm{CNG}(\mathrm{HR}=2.31,95 \% \mathrm{CI}=1.44-3.69, P=0.001), \mathrm{IDH1}$ mutations $(\mathrm{HR}=0.3,95 \% \mathrm{CI}=0.17-0.53, P<0.001)$, increasing age $(\mathrm{HR}=1.52,95 \% \mathrm{CI}=1.16-1.98, P=0.002)$, advanced tumor stage $(\mathrm{HR}=1.92,95 \% \mathrm{CI}=1.47-2.48, P$ $<0.001)$ and tumor recurrence ( $\mathrm{HR}=44.86,95 \% \mathrm{CI}=6.16$ $327.00, P<0.001)$ were significantly correlated with poor survival, while the patients receiving radiotherapy (HR $=0.47,95 \% \mathrm{CI}=0.30-0.75, P<0.001)$ and the patients with epilepsy ( $\mathrm{HR}=0.41,95 \% \mathrm{CI}=0.25-0.66, P<0.001)$ were more likely to have a better prognosis. To further determine clinical value of $\mathrm{CNG}$ of members of $\mathrm{ErbB}$ family in predicting patient survival, we conducted multivariate Cox regression analysis. As shown in Table 5, $\mathrm{CNG}$ of $E G F R(\mathrm{HR}=3.08,95 \% \mathrm{CI}=1.82-5.19, P<0.001)$, 
Table 4: Prognostic value of clinicopathological factors and CNG of members of ErbB family using univariate Cox regression analysis

\begin{tabular}{|c|c|c|}
\hline Characteristics & $H^{*}(95 \%$ CI $)$ & $P$ \\
\hline EGFR $C N G$ & $2.31(1.44-3.69)$ & 0.001 \\
\hline HER2 CNG & $1.21(0.75-1.92)$ & 0.44 \\
\hline HER3 CNG & $1.36(0.85-2.15)$ & 0.19 \\
\hline HER $4 C N G$ & $1.29(0.82-2.03)$ & 0.28 \\
\hline Gender & $0.82(0.52-1.30)$ & 0.39 \\
\hline Age $^{1}$ & $1.52(1.16-1.98)$ & 0.002 \\
\hline WHO grade ${ }^{2}$ & $1.92(1.47-2.48)$ & 0.001 \\
\hline KPS score ${ }^{3}$ & $1.38(0.86-2.21)$ & 0.18 \\
\hline Recurrence & $44.86(6.16-327.00)$ & $<0.001$ \\
\hline Radiotherapy & $0.47(0.30-0.75)$ & $<0.001$ \\
\hline Chemotherapy & $1.45(0.92-2.30)$ & 0.11 \\
\hline Smoking & $1.55(0.96-2.50)$ & 0.07 \\
\hline Drinking & $0.84(0.31-2.30)$ & 0.73 \\
\hline Epilepsy & $0.41(0.25-0.66)$ & $<0.001$ \\
\hline IDH1 mutations & $0.30(0.17-0.53)$ & $<0.001$ \\
\hline
\end{tabular}

${ }^{*} \mathrm{HR}$ : hazard ratio with $95 \%$ confidence interval (CI); ${ }^{1}$ Age (per 20 years); ${ }^{2} \mathrm{WHO}$ grade (I, II, III and IV); ${ }^{3} \mathrm{KPS}(>80 ; \leq 80)$. The cases $<4$ copies were used as reference.

Table 5: Prognostic value of clinicopathological factors and CNG of members of ErbB family using multivariate Cox regression analysis

\begin{tabular}{|c|c|c|c|c|c|c|c|c|}
\hline \multirow{2}{*}{ Characteristics } & \multicolumn{2}{|l|}{ EGFR } & \multicolumn{2}{|l|}{ HER2 } & \multicolumn{2}{|l|}{ HER3 } & \multicolumn{2}{|l|}{ HER4 } \\
\hline & $\mathrm{HR}^{*}(95 \% \mathrm{CI})$ & $P$ & $\mathrm{HR}^{*}(95 \% \mathrm{CI})$ & $P$ & HR $^{*}(95 \%$ CI) & $P$ & $\mathrm{HR}^{*}(95 \% \mathrm{CI})$ & $P$ \\
\hline \multicolumn{9}{|l|}{ Copy number } \\
\hline$\leq 4$ & 1.00 (reference) & & 1.00 (reference) & & 1.00 (reference) & & 1.00 (reference) & \\
\hline$>4$ & $3.08(1.82-5.19)$ & $<0.001$ & $1.66(0.97-2.85)$ & 0.06 & $1.71(1.06-2.76)$ & 0.03 & $1.76(1.08-2.87)$ & 0.02 \\
\hline \multicolumn{9}{|l|}{ Ages } \\
\hline 20/years & $1.35(1.02-1.78)$ & 0.03 & $1.60(1.22-2.10)$ & $<0.001$ & $1.52(1.15-1.99)$ & 0.003 & $1.54(1.18-2.00)$ & 0.002 \\
\hline \multicolumn{9}{|l|}{ WHO grade } \\
\hline I & 1.00 (reference) & & 1.00 (reference) & & 1.00 (reference) & & 1.00 (reference) & \\
\hline II & $2.44(1.04-5.74)$ & 0.04 & $1.37(0.60-3.10)$ & 0.45 & $1.77(0.77-4.04)$ & 0.18 & $1.80(0.78-4.12)$ & 0.17 \\
\hline III & $7.69(3.14-18.88)$ & $<0.001$ & $4.60(1.98-10.73)$ & $<0.001$ & $5.60(2.34-13.39)$ & $<0.001$ & $5.43(2.29-12.90)$ & $<0.001$ \\
\hline IV & $5.98(2.37-15.11)$ & $<0.001$ & $3.89(1.53-9.90)$ & 0.004 & $5.93(2.34-15.06)$ & $<0.001$ & $6.74(2.57-17.72)$ & $<0.001$ \\
\hline \multicolumn{9}{|l|}{ Radiotherapy } \\
\hline No & 1.00 (reference) & & 1.00 (reference) & & 1.00 (reference) & & 1.00 (reference) & \\
\hline Yes & $0.40(0.25-0.66)$ & $<0.001$ & $0.50(0.31-0.80)$ & 0.004 & $0.51(0.32-0.81)$ & 0.004 & $0.51(0.32-0.81)$ & 0.004 \\
\hline \multicolumn{9}{|l|}{ Epilepsy } \\
\hline No & 1.00 (reference) & & 1.00 (reference) & & 1.00 (reference) & & 1.00 (reference) & \\
\hline Yes & $0.44(0.26-0.74)$ & 0.002 & $0.40(0.24-0.68)$ & $<0.001$ & $0.43(0.25-0.72)$ & $<0.001$ & $0.40(0.24-0.67)$ & $<0.001$ \\
\hline
\end{tabular}

*HR: hazard ratio with 95\% confidence interval (CI). 
HER3 $(\mathrm{HR}=1.71,95 \% \mathrm{CI}=1.06-2.76, P=0.03)$ and $H E R 4$ $(\mathrm{HR}=1.76,95 \% \mathrm{CI}=1.08-2.87, P=0.02)$ was identified as independent predictors of poor patient survival with respect to ages, WHO grade, radiotherapy and epilepsy.

Next, we conducted the Kaplan-Meier survival analysis to further validate the effect of $\mathrm{CNG}$ of the above genes on survival. As expected, there was a significantly poorer survival in the patients with EGFR CNG than those without EGFR CNG (18.0 months vs. 36.0 months; $P=0.001$ ) (Figure 2A). This was supported by the TCGA dataset that high copy number of EGFR was strongly related with worse patient survival as compared to low copy number $(P=0.001)$ (Figure $2 \mathrm{~B})$. In addition, the TCGA dataset also showed that high copy number of HER2 ( $P$ $=0.007)$ and HER4 $(P=0.006)$ was significantly associated with poor patient survival (Figure 2); however, we did not find significant relationships between $\mathrm{CNG}$ of HER2 and HER4 and poor patient survival. One possibility is a limited number of glioma patients included in the present study.

Further stratified analysis revealed that $\mathrm{CNG}$ of members of ErbB family almost did not influence median survival times of male patients except for EGFR (28.3 months vs. 50.4 months, $P=0.008)$; however, $\mathrm{CNG}$ of EGFR (31.1 months vs. 49.6 months, $P=0.01$ ), HER2 (30.8 months vs. 46.6 months, $P=0.02$ ) and HER3 (29.3 months vs. 44.1 months, $P=0.05)$ dramatically shortened median survival times in female patients (Figure $3 \mathrm{~A}$ and Table 6). It is well known that tumor grade significantly affects patient survival, which was supported by our data that tumor grade was positively associated with poor patient survival (Table 5). Thus, the data were stratified according to tumor grade, and prognostic value of $\mathrm{CNG}$ of these genes was further evaluated in these patients. As shown in Figure 3B and Table 6, we found that CNG of the above genes had very little effect on the survival of the patients with GBM, while CNG of EGFR (40.2 months vs. 71.4 months, $P=0.001$ ), HER3 (44.8 months vs. 58.2 months, $P=0.02$ ) and HER4 (46.2 months vs. 57.7 months, $P=0.03$ ) significantly shortened median survival times of the patients with LGG. In addition, given that IDHI mutation lead to a better prognosis of glioma patients, we next evaluated the effect of CNG of these genes on the survival of the patients with different IDHI mutation status. The results showed that $\mathrm{CNG}$ of EGFR (40.2 months vs. 71.5 months, $P=0.004), H E R 3$ (46.7 months vs. 63.9 months, $P=0.008)$ and HER4 (47.4 months vs. 64.8 months, $P=0.007$ ) significantly shortened median survival times of the patients with $I D H 1$ mutation, but no effect on the survival of those without IDH1 mutations (Figure 4 and Supplementary Table 6).

\section{Impact of CNG of members of ErbB family on radiotherapy outcome of glioma patients}

It is the fact that postoperative adjuvant radiotherapy may improve survival after surgical resection for glioma. Indeed, our data showed that radiotherapy significantly lengthened median survival of glioma patients (Table 5).
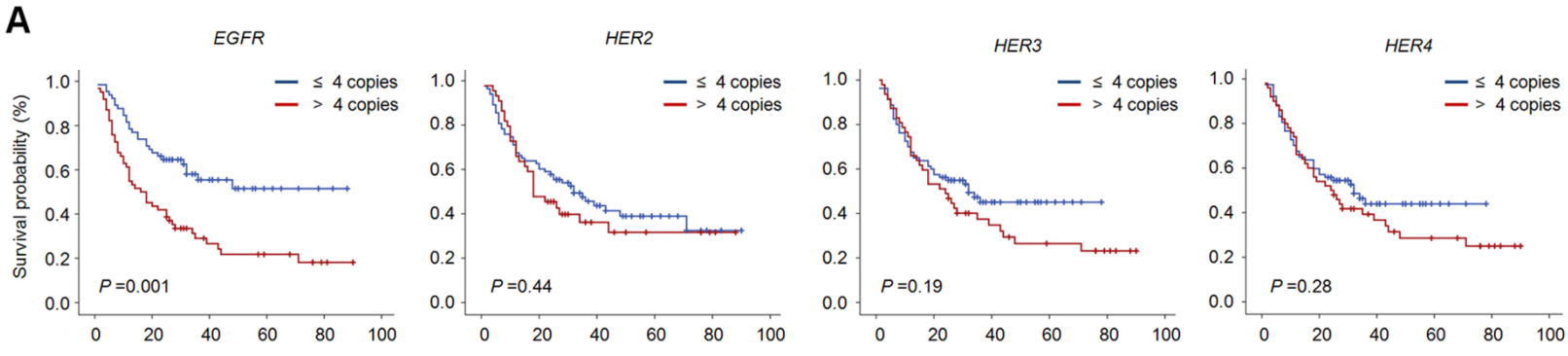

Survival time after surgery (months)
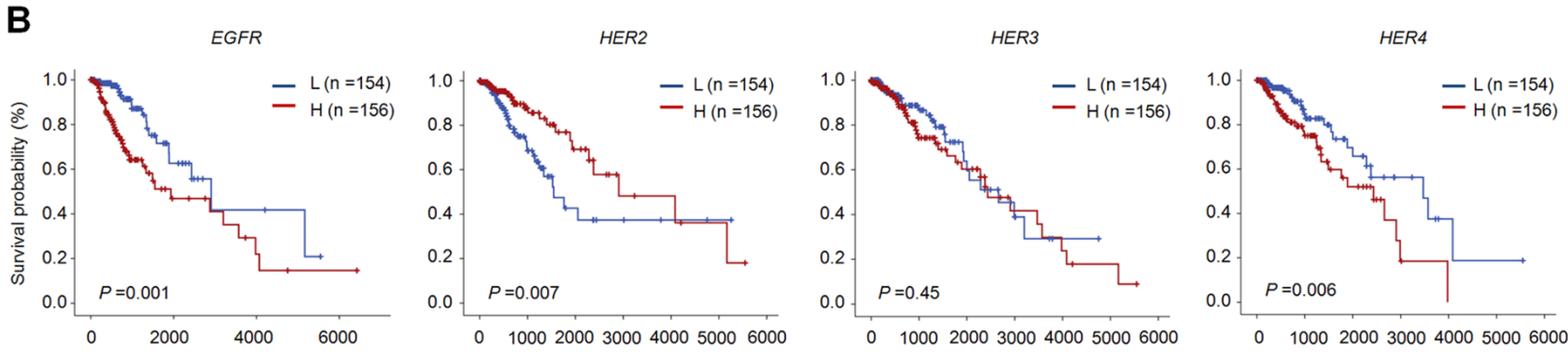

Survival time after surgery (days)

Figure 2: The effect of CNG of members of ErbB family on the survival of glioma patients. Kaplan-Meier survival curves were grouped based on the status of CNG of the indicated gene in gliomas from our cohort (A) and TCGA cohort (B)." $L$ " and " $H$ " represent low- and high-copy number of the indicated gene, respectively. A median copy number of each indicated gene is used as cut-off value. 
Thus, in the present study, we further evaluated the prognostic value of $\mathrm{CNG}$ of members of ErbB family in the patients receiving radiotherapy. As shown in Figure 5 and Table 6 , CNG of these genes dramatically shortened median survival times in the patients receiving radiotherapy (EGFR: 36.0 months vs. 67.0 months, $P$ $=0.001$; HER2: 40.0 months vs. 60.0 months, $P=0.04$; HER3: 41.5 months vs. 52.1 months, $P=0.06$; HER 4: 41.8 months vs. 52.6 months, $P=0.05)$, but not in those who did not receive radiotherapy except for EGFR (18.1 months vs. 30.3 months, $P=0.02$ ). In addition, we did not find significant effect of $\mathrm{CNG}$ of these genes on chemotherapy in glioma patients (data not shown). Taken together, our data suggest that CNG of HER2-4 genes may be used as predictors of radiotherapy resistance in gliomas.

\section{DISCUSSION}

Gliomas are the most common and the deadliest brain malignancies all over the world. In general, the progression of glioma is a long-term process with accumulation of a large number of genetic and epigenetic alterations. Genomic amplification, a common mechanism for oncogene overexpression, is one of the most frequent genomic alterations found in human cancers including gliomas [20-27]. It is well-documented that the ErbB family of RTKs has a critical role in the tumorigenesis of many types of cancer [14]. Its members including EGFR, HER2, HER3 and HER4 have been reported to be frequently amplified in different types of cancer including gliomas [28, 29]. However, their clinical significance
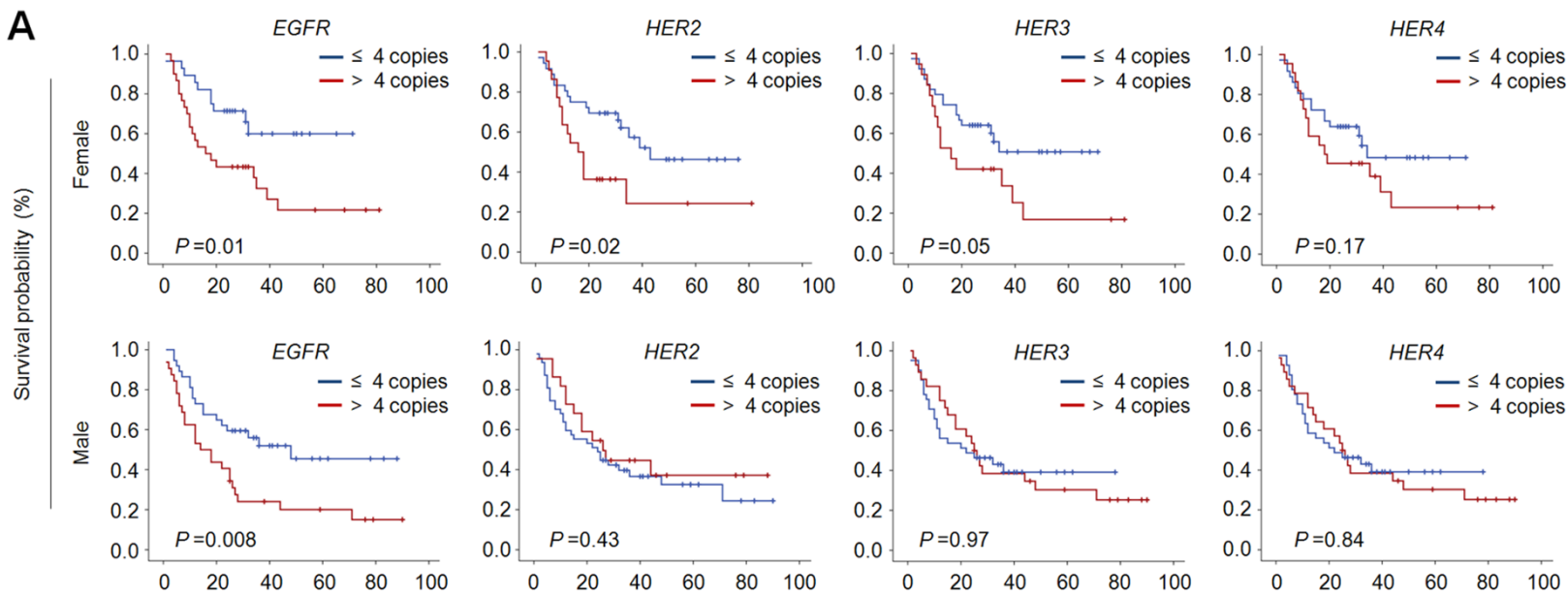

Survival time after surgery (months)
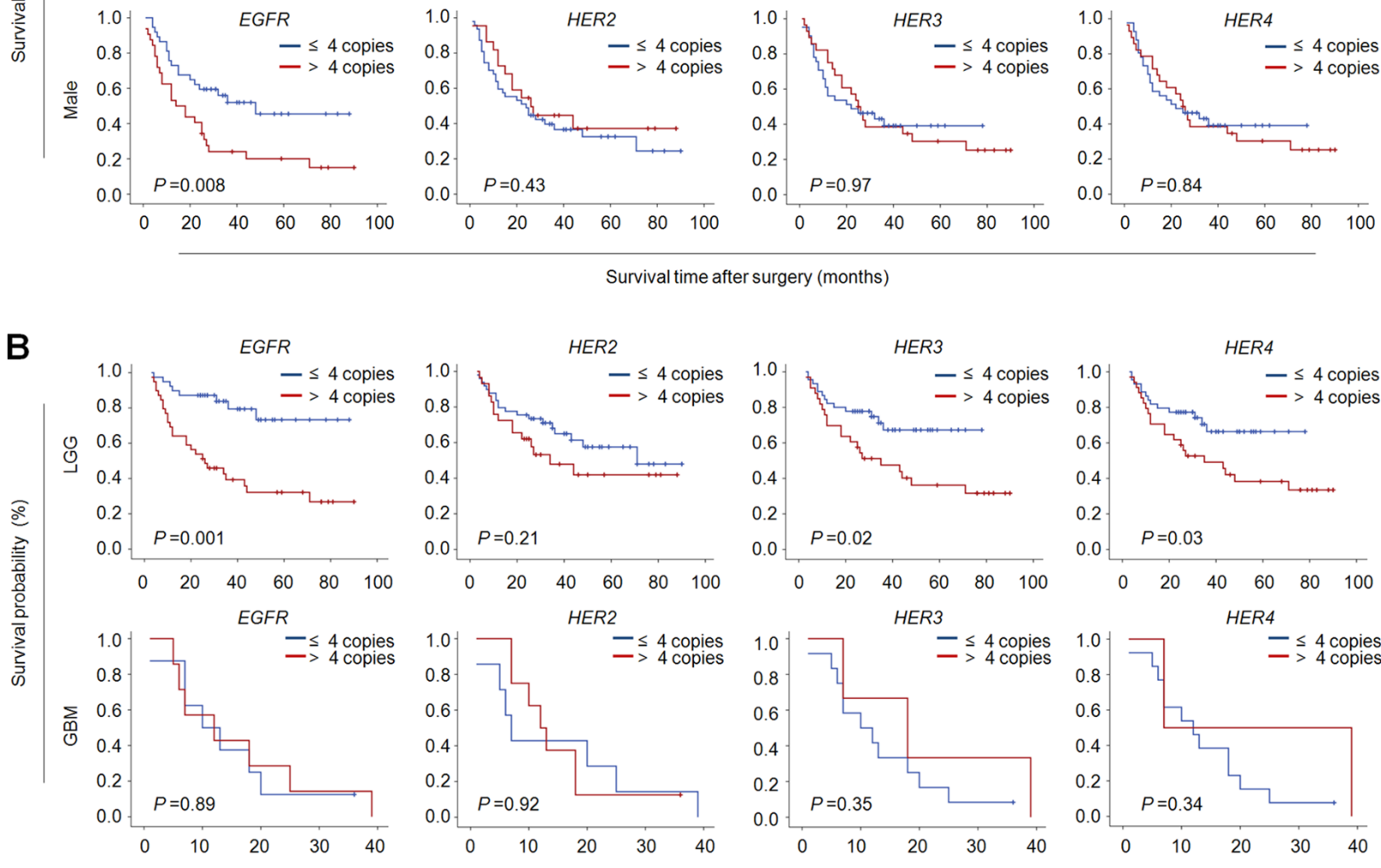

Survival time after surgery (months)

Figure 3: The associations of CNG of members of ErbB family with poor survival of female and low-grade glioma patients. Kaplan-Meier survival curves were grouped similar to that shown in Figure 2. (A) CNG of members of ErbB family particularly EGFR, HER2 and HER3 dramatically shortened median survival times in female patients, but not male patients except for EGFR. (B) CNG of the indicated genes particularly EGFR, HER3 and HER4 significantly shortened median survival times in LCCs, but not in GBMs. 
Table 6: The median survival times by grouping with CNG of members of ErbB family

\begin{tabular}{|c|c|c|c|c|c|c|c|c|c|c|c|c|c|c|}
\hline \multirow{2}{*}{$\begin{array}{l}\text { Copy } \\
\text { number }\end{array}$} & \multicolumn{2}{|c|}{ Overall } & \multicolumn{2}{|l|}{ Female } & \multicolumn{2}{|l|}{ Male } & \multicolumn{2}{|l|}{$\begin{array}{l}\text { LGG } \\
\text { (I/II) }\end{array}$} & \multicolumn{2}{|c|}{$\begin{array}{c}\text { GBM } \\
\text { (IV) }\end{array}$} & \multicolumn{2}{|c|}{ Radiotherapy } & \multicolumn{2}{|c|}{ Non-Radiotherapy } \\
\hline & $\begin{array}{c}\text { Median, } \\
\text { months } \\
(95 \% \text { CI })\end{array}$ & $P$ & $\begin{array}{c}\text { Median, } \\
\text { months } \\
(95 \% \text { CI })\end{array}$ & $P$ & $\begin{array}{c}\text { Median, } \\
\text { months } \\
(95 \% \text { CI })\end{array}$ & $P$ & $\begin{array}{c}\text { Median, } \\
\text { months } \\
(95 \% \text { CI })\end{array}$ & $P$ & $\begin{array}{c}\text { Median, } \\
\text { months } \\
(95 \% \mathrm{CI})\end{array}$ & $P$ & $\begin{array}{c}\text { Median, } \\
\text { months } \\
(95 \% \text { CI })\end{array}$ & $P$ & $\begin{array}{c}\text { Median, } \\
\text { months } \\
(95 \% \mathrm{CI})\end{array}$ & $P$ \\
\hline \multicolumn{15}{|l|}{$E G F R$} \\
\hline$\leq 4$ & $\begin{array}{c}54.4 \\
(45.1-63.8)\end{array}$ & \multirow{2}{*}{0.001} & $\begin{array}{c}49.6 \\
(39.0-60.2)\end{array}$ & \multirow{2}{*}{0.01} & $\begin{array}{c}50.4 \\
(38.1-62.8)\end{array}$ & \multirow{2}{*}{0.008} & $\begin{array}{c}71.4 \\
(61.2-81.5)\end{array}$ & \multirow{2}{*}{0.001} & $\begin{array}{c}10.0 \\
(1.7-18.3)\end{array}$ & \multirow{2}{*}{0.89} & $\begin{array}{c}67.0 \\
(56.6-78.4)\end{array}$ & \multirow{2}{*}{0.001} & $\begin{array}{c}30.3 \\
(21.2-39.5)\end{array}$ & \multirow[t]{2}{*}{0.02} \\
\hline$>4$ & $\begin{array}{c}31.0 \\
(22.7-39.2)\end{array}$ & & $\begin{array}{c}31.1 \\
(20.1-42.2)\end{array}$ & & $\begin{array}{c}28.3 \\
(17.5-39.1)\end{array}$ & & $\begin{array}{c}40.2 \\
(29.1-51.3)\end{array}$ & & $\begin{array}{c}12.0 \\
(0.0-24.8)\end{array}$ & & $\begin{array}{c}36.0 \\
(26.0-46.1)\end{array}$ & & $\begin{array}{c}18.1 \\
(6.8-29.4)\end{array}$ & \\
\hline \multicolumn{15}{|l|}{ HER2 } \\
\hline$\leq 4$ & $\begin{array}{c}44.4 \\
(36.0-52.8)\end{array}$ & \multirow{2}{*}{0.43} & $\begin{array}{c}46.6 \\
(36.1-57.1)\end{array}$ & \multirow{2}{*}{0.02} & $\begin{array}{c}38.0 \\
(27.5-48.6)\end{array}$ & \multirow{2}{*}{0.40} & $\begin{array}{c}59.1 \\
(48.5-69.7)\end{array}$ & \multirow{2}{*}{0.21} & $\begin{array}{c}7.0 \\
(4.4-9.6)\end{array}$ & \multirow{2}{*}{0.92} & $\begin{array}{c}60.0 \\
(46.2-67.7)\end{array}$ & \multirow{2}{*}{0.04} & $\begin{array}{c}25.6 \\
(16.3-34.9)\end{array}$ & \multirow[t]{2}{*}{0.54} \\
\hline$>4$ & $\begin{array}{c}38.7 \\
(28.0-49.7)\end{array}$ & & $\begin{array}{c}30.8 \\
(16.5-45.1)\end{array}$ & & $\begin{array}{c}44.2 \\
(29.0-59.4)\end{array}$ & & $\begin{array}{c}47.9 \\
(34.1-61.7)\end{array}$ & & $\begin{array}{c}12.0 \\
(7.8-16.2)\end{array}$ & & $\begin{array}{c}40.0 \\
(27.4-52.8)\end{array}$ & & $\begin{array}{c}34.7 \\
(16.9-52.6)\end{array}$ & \\
\hline \multicolumn{15}{|l|}{ HER3 } \\
\hline$\leq 4$ & $\begin{array}{c}42.9 \\
(35.4-50.4)\end{array}$ & \multirow{2}{*}{0.18} & $\begin{array}{c}44.1 \\
(34.6-53.7)\end{array}$ & \multirow{2}{*}{0.05} & $\begin{array}{c}38.1 \\
(27.7-48.4)\end{array}$ & \multirow{2}{*}{0.97} & $\begin{array}{c}58.2 \\
(49.2-67.2)\end{array}$ & \multirow{2}{*}{0.02} & $\begin{array}{c}10.0 \\
(1.5-18.5)\end{array}$ & \multirow{2}{*}{0.35} & $\begin{array}{c}52.1 \\
(42.7-61.5)\end{array}$ & \multirow{2}{*}{0.06} & $\begin{array}{c}25.7 \\
(17.0-34.5)\end{array}$ & \multirow{2}{*}{0.59} \\
\hline$>4$ & $\begin{array}{c}36.9 \\
(27.3-46.6)\end{array}$ & & $\begin{array}{c}29.3 \\
(16.5-42.1)\end{array}$ & & $\begin{array}{c}39.6 \\
(27.2-52.1)\end{array}$ & & $\begin{array}{c}44.8 \\
(32.7-56.9)\end{array}$ & & $\begin{array}{c}18.0 \\
(0.4-35.6)\end{array}$ & & $\begin{array}{c}41.5 \\
(30.0-53.1)\end{array}$ & & $\begin{array}{c}25.4 \\
(11.2-39.6)\end{array}$ & \\
\hline \multicolumn{15}{|l|}{ HER4 } \\
\hline$\leq 4$ & $\begin{array}{c}42.4 \\
(34.7-50.0)\end{array}$ & \multirow{2}{*}{0.27} & $\begin{array}{c}42.9 \\
(32.7-53.1)\end{array}$ & \multirow{2}{*}{0.18} & $\begin{array}{c}38.5 \\
(28.3-48.7)\end{array}$ & 0.4 & $\begin{array}{c}57.7 \\
(48.4-66.9)\end{array}$ & 003 & $\begin{array}{c}13.7 \\
(8.7-18.7)\end{array}$ & 034 & $\begin{array}{c}52.6 \\
(43.1-62.1)\end{array}$ & 005 & $\begin{array}{c}23.9 \\
(15.2-32.6)\end{array}$ & 0.97 \\
\hline$>4$ & $\begin{array}{c}38.2 \\
(28.6-47.7)\end{array}$ & & $\begin{array}{c}33.6 \\
(20.6-46.5)\end{array}$ & & $\begin{array}{c}39.0 \\
(26.4-51.7)\end{array}$ & ד. & $\begin{array}{c}46.2 \\
(34.2-58.1)\end{array}$ & 0.0 & $\begin{array}{c}23.0 \\
(0.0-54.4)\end{array}$ & דנס & $\begin{array}{c}41.8 \\
(30.3-53.2)\end{array}$ & & $\begin{array}{c}28.4 \\
(13.8-42.9)\end{array}$ & \\
\hline
\end{tabular}

in the prognostic evaluation of glioma patients remains largely unclear.

In the present study, we measured copy number of members of ErbB family (including EGFR, HER2, HER3 and HER4) in a cohort of glioma patients and control subjects using real-time qPCR approach and determined their prognostic significance in gliomas. Our data showed that these genes were frequently amplified in gliomas, but not in control subjects. This was consistent with a previous study that $E G F R$ amplification was frequently found in gliomas and could be used as a biomarker for the diagnosis of this cancer [30]. These observations suggest that $\mathrm{CNG}$ of members of ErbB family is more likely involved in glioma tumorigenesis. To further explore the associations of these aberrant genetic events with clinicopathological characteristics and clinical outcomes of glioma patients, we defined a copy number of $\geq 4$ as $\mathrm{CNG}$ (or gene amplification), the patients were then categorized into two groups: CNG- and Non-CNGgroups. The results demonstrated that $\mathrm{CNG}$ of $E G F R$, HER 3 and HER 4 significantly increased the risk of cancerrelated death in glioma patients. This was supported by the findings in some other cancers. For example, CNGs of EGFR, HER2, HER3, and HER4 had strongly associations with poor overall survival in lung adenocarcinoma with
EGFR-activating mutations [31]. In addition, our data also showed that EGFR, HER3 and HER4 genes were more likely to be amplified in the patients with early-stage tumors, suggesting that these aberrations may be earlystage genetic events, contributing to tumor initiation and tumorigenesis. Interestingly, we found that $\mathrm{CNG}$ of $E G F R$ and HER2 was more frequently found in the patients receiving postoperative radiotherapy as compared to those who did not receiving radiotherapy, whereas $\mathrm{CNG}$ of HER3 and HER4 was more frequently found in the patients who did not receive postoperative chemotherapy relative to those receiving chemotherapy. These data suggest that $\mathrm{CNG}$ of $E G F R$ and HER2 may be involved in radiotherapy resistance in gliomas, while CNG of $H E R 3$ and HER 4 may be used as predictors for the sensitivity of glioma cells to chemotherapy. Notably, our data also showed distinct roles of $\mathrm{CNG}$ of these genes in female and male patients. However, these findings need to be further validated and elucidated.

Next, we attempted to test the effect of CNG of these genes on clinical outcomes of glioma patients. As expected, our data and the TCGA database showed that $\mathrm{CNG}$ of some of these genes was significantly associated with poor patient survival particularly EGFR. By using stratified analysis, we surprisingly found that $\mathrm{CNG}$ of 
EGFR, HER2 and HER3 remarkably shortened median survival times in female patients, but almost did not influence the survival of male patients except for EGFR. Similarly, these findings also need to be further confirmed and elucidated. In addition, our data also showed that CNG of EGFR, HER3 and HER4 significantly shortened median survival times of the patients with early-stage tumors, but had very little effect on the survival of the patients with late-stage tumors, further supporting that these abnormalities may be early genetic events in glioma tumorigenesis. However, a previous study has demonstrated mutation rate of EGFR in lung cancer differs between races [32]. Given that the patients investigated in our cohort and TCGA cohort are from different races, thus

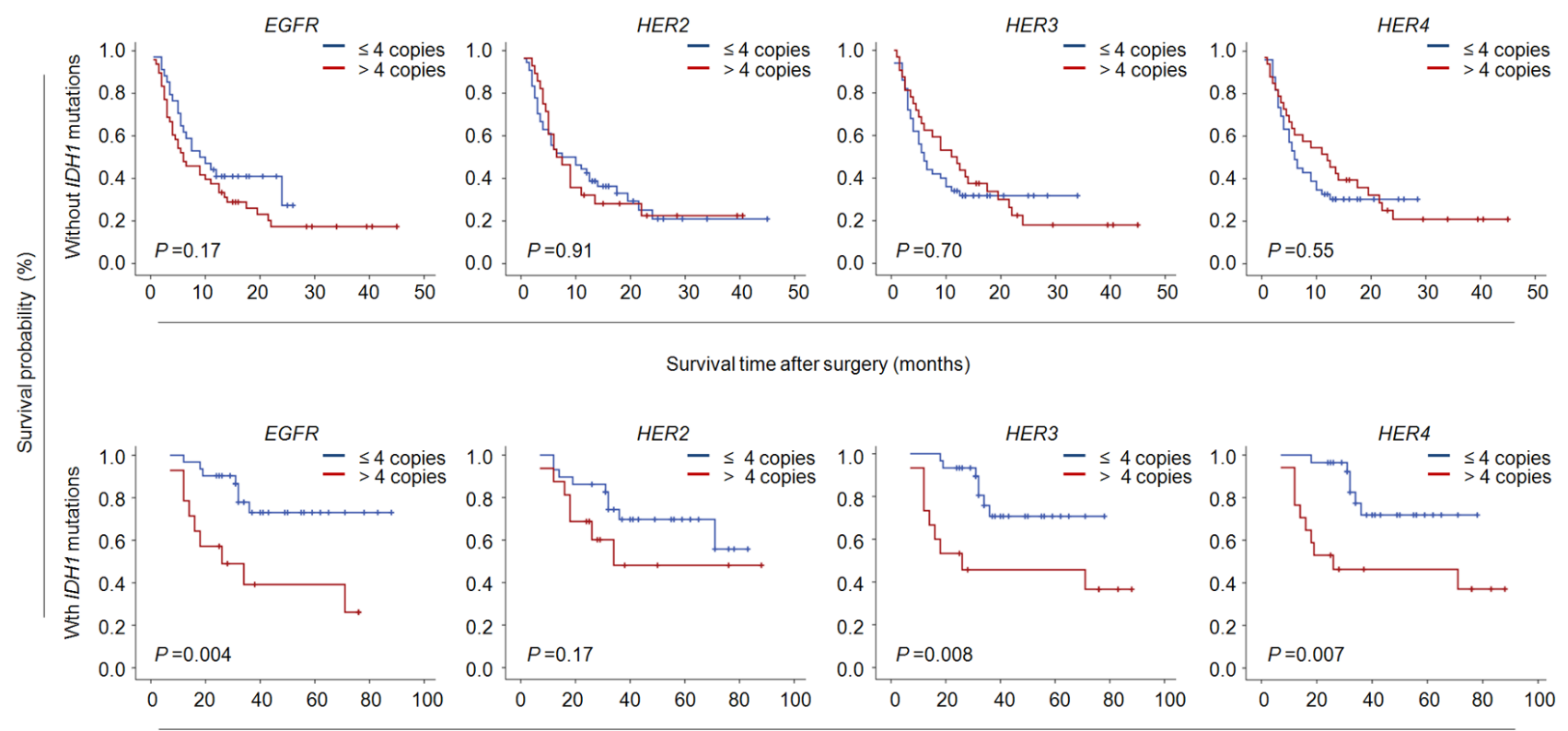

Survival time after surgery (months)

Figure 4: Association of CNG of ErbB family members with poor survival of glioma patients with IDH1 mutations. Kaplan-Meier survival curves were grouped based on the status of IDH1 mutations. CNG of members of ErbB family dramatically shortened median survival times in the patients with $I D H 1$ mutations except for HER2, while no effect on the survival of the patients without IDHI mutations.

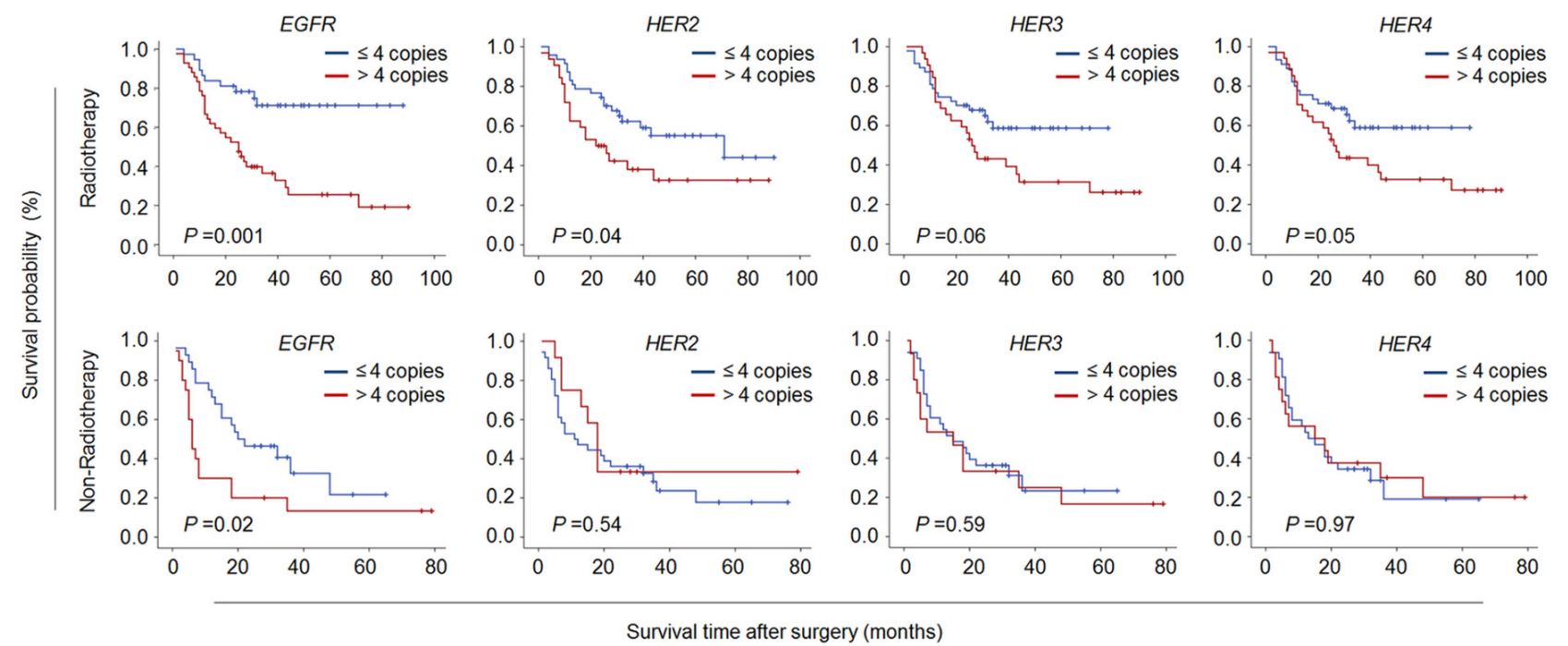

Figure 5: The associations of CNG of members of ErbB family with radiotherapy resistance in glioma patients. KaplanMeier survival curves were grouped similar to that shown in Figure 2. CNG of members of ErbB family dramatically shortened median survival times in the patients receiving radiotherapy, but not in those who did not receive radiotherapy except for $E G F R$. 
we speculate that different race backgrounds may lead to some different correlations between CNGs of ErbB family members and clinicopathological characteristics in glioma patients.

It is well known that radiotherapy is a part of multidisciplinary management of several cancers including gliomas. Moreover, there is increasing evidence showing that combined treatment of chemotherapy and radiotherapy is more effective in the care of gliomas as compared to radiotherapy alone $[33,34]$. In recent years, several clinical trials of molecularly targeted cancer therapies in glioma have been conducted based on the known functions of the receptors of ErbB family $[35,36]$. The two major classes of anti-ErbB therapeutics are monoclonal antibodies and small molecule tyrosine kinase inhibitors (TKI) [37]. AC480 is a highly selective and potent small-molecule inhibitor of EGFR/HER kinase family, and inhibit cancer cell proliferation through targeting EGFR and HER2 kinases [38]. Moreover, AC480 has been demonstrated to enhance radiosensitivity and radioresponse of head and neck squamous cell carcinoma cells in vitro and in vivo [39]. Notably, we found that $\mathrm{CNG}$ of members of ErbB family significantly impacted radiotherapy outcome of glioma patients. CNG of these genes significantly shortened median survival times in the patients receiving radiotherapy. However, the underlying mechanism is still unclear. There is evidence showing that the PI3K/AKT/mTOR cascade has been considered as the predominant downstream pathway of ErbB kinases, promoting radioresistance in various types of cancer including glioma [40-44]. Therefore, we suppose that $\mathrm{CNG}$ of members of ErbB family in gliomas induces radiotherapy resistance through activating the PI3K/AKT pathway. Taken together, our data suggest that the combination of TKIs and radiotherapy may be a eutherapeutic strategy for glioma patients with CNG of members of ErbB family, which is strongly supported by several previous studies [45-48].

In summary, our data found frequent $\mathrm{CNG}$ of members of ErbB family in patients, and demonstrated that these abnormalities were significantly associated with poor clinical outcomes of glioma patients, particularly in female or low-grade glioma patients. To our knowledge, the present study for the first time demonstrates that $\mathrm{CNG}$ of members of ErbB family may contribute to radiotherapy resistance in glioma patients. Altogether, our findings indicate that the above abnormalities may be a trigger of glioma tumorigenesis, and may be used as potentially prognostic markers for glioma patients. In addition, our data also suggest that a combination of anti-ErbB therapeutics and radiotherapy may be an effective strategy for the treatment of glioma patients with $\mathrm{CNG}$ or overactivation of members of ErbB family.

\section{MATERIALS AND METHODS}

\section{Patients and tissue samples}

With the approval of our institutional review board and human ethics committee, a total of 127 glioma patients and 16 benign meningiomas as control subjects, who underwent surgery for brain tumors at the Department of Neurosurgery of First Affiliated Hospital of Xi'an Jiaotong University from 2006 to 2012, were randomly enrolled in this study (Supplementary Table 1). None of these patients receive radiotherapy or chemotherapy prior to surgery. Glioma patients received adjuvant radiotherapy and/or chemotherapy after surgery according to standard clinical protocols. All samples were histopathologically classified according to the WHO classification criteria. Overall survival was calculated as time duration starting from surgery until cancer-related death or last follow-up. Clinicopathological data were obtained from the patients' files or by interview with the patients or their relatives, and were summarized in Table 1. All patients were enrolled after providing a written informed consent.

\section{DNA preparation}

Formalin-fixed paraffin-embedded tissues from each sample were cut at $5 \mathrm{~mm}$, and all tissue sections were reviewed by board-certified pathologists to ensure containing more than $50 \%$ tumor cells. DNA was then extracted according to a previously described protocol [49]. In brief, the sections were first treated with xylene for $12 \mathrm{~h}$ at room temperature for deparaffinization, followed by digestion with $1 \%$ sodium dodecylsulfate (SDS) and proteinase $\mathrm{K}$ at $48^{\circ} \mathrm{C}$ for $48 \mathrm{~h}$. Genomic DNA was then isolated from these tissues using a standard protocol.

\section{Copy number analysis}

Copy number of members of ErbB family was analyzed in gliomas and control subjects by a wellestablished real-time qPCR approach, which was previously validated by fluorescence in situ hybridization (FISH) [50]. Primer Express 3.0 software (Applied Biosystems, Foster City, CA) was utilized to design specific PCR primers and TaqMan probes for the amplification of the indicated genes and internal control $\beta$-actin. TaqMan probes were labeled at the 5 ' end with a fluorescent reporter 6-carboxyfluorescein (6FAM) and at the 3 ' end with a fluorescent quencher 6-carboxytetramethylrhodamine (TAMRA). The sequences were presented in Supplementary Table 7. The PCR reaction was performed according to a previously described protocol $[50,51]$. Each sample was run in triplicate, and $\beta$-actin was performed in parallel to normalize the input DNA. Serially diluted leukocyte DNA was used to establish standard curves. Copy number was calculated as 
previously described. A copy number $\geq 4$ was defined as gene amplification (or copy number gain).

\section{Detection of $I D H 1$ mutations}

A fragment of $129 \mathrm{bp}$ length spanning the catalytic domain of IDH1 including codon 132 was amplified by PCR with the following primers: 5'-CGG TCT TCA GAG AAG CCA TT-3' (forward) and 5'-GCA AAA TCA CAT TAT TGC CAA C-3' (reverse). PCR products were analyzed by Sanger sequencing.

\section{Statistical analysis}

Statistical analysis was performed using the SPSS 15.0 software (Chicago, IL, USA). $P$ value $<0.05$ was considered statistically significant. Mann-Whitney $U$-test was applied to compare copy number of the indicated genes between gliomas and control subjects. SPSS 15.0 software was used for the univariately logistic regression analysis of the association of $\mathrm{CNG}$ of the indicated genes with clinicopathological features of giloma patients. Multivariate analysis was performed to calculate multivariable-adjusted odds ratios (ORs) and 95\% confidence intervals (CIs) for CNG of the indicated genes, and other factors such as WHO grade, recurrence, radiotherapy, chemotherapy and survival status. Cancerrelated survival was calculated from the date of the operation to cancer-related death or last follow-up. Kaplan-Meier survival analysis was performed to evaluate the impact of CNG of the indicated genes on patient survival. Log-rank test was used to analyze the differences between curves. The effect of $\mathrm{CNG}$ of the indicated genes on the independent survival of age, WHO grade, radiotherapy and epilepsy was determined by multivariate Cox regression analysis.

\section{CONFLICTS OF INTEREST}

The authors declare no conflicts of interest.

\section{FUNDING}

This work was supported by the National Natural Science Foundation of China (No. 81402340, 81472622 and 81572627), and Key Science and Technology Program of Shaanxi Province (No. 2014K11-01-01-19).

\section{REFERENCES}

1. Louis DN, Ohgaki H, Wiestler OD, Cavenee WK, Burger PC, Jouvet A, Scheithauer BW, Kleihues P. The 2007 WHO classification of tumours of the central nervous system. Acta Neuropathol. 2007; 114:97-109.

2. Chen R, Smith-Cohn M, Cohen AL, Colman H. Glioma Subclassifications and Their Clinical Significance.
Neurotherapeutics. 2017; 14:284-297. https://doi.org/10.1007/ s13311-017-0519-X.

3. Rajesh Y, Pal I, Banik P, Chakraborty S, Borkar SA, Dey G, Mukherjee A, Mandal M. Insights into molecular therapy of glioma: current challenges and next generation blueprint. Acta Pharmacol Sin. 2017; 38:591-613. https://doi. org/10.1038/aps.2016.167.

4. Ohgaki H. Epidemiology of brain tumors. Methods Mol Biol. 2009; 472:323-42.

5. Jhaveri N, Chen TC, Hofman FM. Tumor vasculature and glioma stem cells: Contributions to glioma progression. Cancer Lett. 2016; 380:545-51.

6. Liu B, Morrison CD, Johnson CS, Trump DL, Qin M, Conroy JC, Wang J, Liu S. Computational methods for detecting copy number variations in cancer genome using next generation sequencing: principles and challenges. Oncotarget. 2013; 4:1868-81. http://doi.org/10.18632/ oncotarget.1537.

7. Yang H, Liu M, Zhou B, Deng Y, He N, Jiang H, Guo Y, Lan G, Jiang Q, Yang X, Li Z. Chemiluminescent Detection for Estimating Relative Copy Numbers of Porcine Endogenous Retrovirus Proviruses from Chinese Minipigs Based on Magnetic Nanoparticles. J Nanosci Nanotechnol. 2016; 16:6505-10.

8. Liu M, Hu P, Zhang G, Zeng Y, Yang H, Fan J, Jin L, Liu H, Deng Y, Li S, Zeng X, Elingarami S, He N. Copy number variation analysis by ligation-dependent PCR based on magnetic nanoparticles and chemiluminescence. Theranostics. 2015; 5:71-85.

9. Beroukhim R, Zhang X, Meyerson M. Copy number alterations unmasked as enhancer hijackers. Nat Genet. 2016; 49:5-6.

10. Brat DJ, Verhaak RG, Aldape KD, Yung WK, Salama SR, Cooper LA, Rheinbay E, Miller CR, Vitucci M, Morozova O, Robertson AG, Noushmehr H, Laird PW, et al. Cancer Genome Atlas Research Network, Comprehensive, Integrative Genomic Analysis of Diffuse Lower-Grade Gliomas. N Engl J Med. 2015; 372:2481-98.

11. Casaletto JB, McClatchey AI. Spatial regulation of receptor tyrosine kinases in development and cancer. Nat Rev Cancer. 2012; 12:387-400.

12. Graham DK, DeRyckere D, Davies KD, Earp HS. The TAM family: phosphatidylserine sensing receptor tyrosine kinases gone awry in cancer. Nat Rev Cancer. 2014; 14:769-85.

13. Linggi B, Carpenter G. ErbB receptors: new insights on mechanisms and biology. Trends Cell Biol. 2006; 16:649-56.

14. Yarden Y, Pines G. The ERBB network: at last, cancer therapy meets systems biology. Nat Rev Cancer. 2012; 12:553-63.

15. Holbro T, Hynes NE. ErbB receptors: directing key signaling networks throughout life. Annu Rev Pharmacol Toxicol. 2004; 44:195-217. 
16. Wilson KJ, Gilmore JL, Foley J, Lemmon MA, Riese DJ 2nd. Functional selectivity of EGF family peptide growth factors: implications for cancer. Pharmacol Ther. 2009; 122:1-8.

17. Prabhu S, Harris F, Lea R, Snape TJ. Small-molecule clinical trial candidates for the treatment of glioma. Drug Discov Today. 2014; 19:1298-308.

18. Kwon MJ, Kim ST, Kwon MJ, Kong DS, Lee D, Park S, Kang SY, Song JY, Nam DH, Kato Y, Choi YL, Suh YL. Mutated IDH1 is a favorable prognostic factor for type 2 gliomatosis cerebri. Brain Pathol. 2012; 22:307-17.

19. Lu Y, Kwintkiewicz J, Liu Y, Tech K, Frady LN, Su YT, Bautista W, Moon SI, MacDonald J, Ewend MG, Gilbert MR, Yang C, Wu J. Chemosensitivity of IDH1-Mutated Gliomas Due to an Impairment in PARP1-Mediated DNA Repair. Cancer Res. 2017; 77:1709-1718.

20. Mares J, Polanská V, Görgens H, Sedlácek Z, Maríková T, Bocek P, Kodet R, Schackert J, Goetz P. Oncogene amplification and expression in pediatric solid tumors. Neoplasma. 1998; 45:123-7.

21. Ji M, Guan H, Gao C, Shi B, Hou P. Highly frequent promoter methylation and PIK3CA amplification in nonsmall cell lung cancer (NSCLC). BMC Cancer. 2011; 11:147.

22. Shi J, Yao D, Liu W, Wang N, Lv H, He N, Shi B, Hou P, Ji $\mathrm{M}$. Frequent gene amplification predicts poor prognosis in gastric cancer. Int J Mol Sci. 2012; 13:4714-26.

23. Bagci O, Kurtgoz S. Amplification of Cellular Oncogenes in Solid Tumors. N Am J Med Sci. 2015; 7:341-6.

24. Shi J, Liu W, Sui F, Lu R, He Q, Yang Q, Lv H, Shi B, Hou P. Frequent amplification of AIB1, a critical oncogene modulating major signaling pathways, is associated with poor survival in gastric cancer. Oncotarget. 2015; 6:1434459. http://doi.org/10.18632/oncotarget.3852.

25. Wang N, She J, Liu W, Shi J, Yang Q, Shi B, Hou P. Frequent amplification of PTP1B is associated with poor survival of gastric cancer patients. Cell Cycle. 2015; 14:732-43.

26. Shi J, Qu Y, Li X, Sui F, Yao D, Yang Q, Shi B, Ji M, Hou P. Increased expression of EHF via gene amplification contributes to the activation of HER family signaling and associates with poor survival in gastric cancer. Cell Death Dis. 2016; 7:e2442.

27. Chen L, Wang C, Zhang X, Gao K, Liu R, Shi B, Hou P. AIB1 Genomic Amplification Predicts Poor Clinical Outcomes in Female Glioma Patients. J Cancer. 2016; 7:2052-2060.

28. Andersson U, Guo D, Malmer B, Bergenheim AT, Brännström T, Hedman H, Henriksson R. Epidermal growth factor receptor family (EGFR, ErbB2-4) in gliomas and meningiomas. Acta Neuropathol. 2004; 108:135-42.

29. Andersson U, Schwartzbaum J, Wiklund F, Sjöström S, Liu Y, Tsavachidis S, Ahlbom A, Auvinen A, Collatz-Laier H, Feychting M, Johansen C, Kiuru A, Lönn S, et al. A comprehensive study of the association between the EGFR and ERBB2 genes and glioma risk. Acta Oncol. 2010; 49:767-75.

30. Jeuken J, Sijben A, Alenda C, Rijntjes J, Dekkers M, BootsSprenger S, McLendon R, Wesseling P. Robust detection of EGFR copy number changes and EGFR variant III: technical aspects and relevance for glioma diagnostics. Brain Pathol. 2009; 19:661-71.

31. Chen HY, Liu CH, Chang YH, Yu SL, Ho BC, Hsu CP, Yang TY, Chen KC, Hsu KH, Tseng JS, Hsia JY, Chuang $\mathrm{CY}$, Chang CS, et al. EGFR-activating mutations, DNA copy number abundance of ErbB family, and prognosis in lung adenocarcinoma. Oncotarget. 2016; 7:9017-25. http:// doi.org/10.18632/oncotarget.7029.

32. Steuer CE, Behera M, Berry L, Kim S, Rossi M, Sica G, Owonikoko TK, Johnson BE, Kris MG, Bunn PA, Khuri FR, Garon EB, Ramalingam SS. Role of race in oncogenic driver prevalence and outcomes in lung adenocarcinoma: Results from the Lung Cancer Mutation Consortium. Cancer. 2016; 122:766-72.

33. Parisi S, Corsa P, Raguso A, Perrone A, Cossa S, Munafò T, Sanpaolo G, Donno E, Clemente MA, Piombino M, Parisi F, Valle G. Temozolomide and radiotherapy versus radiotherapy alone in high grade gliomas: a very long term comparative study and literature review. Biomed Res Int. 2015; 2015:620643.

34. Buckner JC, Shaw EG, Pugh SL, Chakravarti A, Gilbert MR, Barger GR, Coons S, Ricci P, Bullard D, Brown PD, Stelzer K, Brachman D, Suh JH, et al. Radiation plus Procarbazine, CCNU, and Vincristine in Low-Grade Glioma. N Engl J Med. 2016; 374:1344-55.

35. Ridler C. Neuro-oncology: New therapeutic targets for diffuse intrinsic pontine glioma. Nat Rev Neurol. 2017; 13:196.

36. Yao TW, Zhang J, Prados M, Weiss WA, James CD, Nicolaides T. EGFR blockade prevents glioma escape from BRAFV600E targeted therapy. Oncotarget. 2015; 6:219932005. http://doi.org/10.18632/oncotarget.4014.

37. Greenall SA, Donoghue JF, Van Sinderen M, Dubljevic V, Budiman S, Devlin M, Street I, Adams TE, Johns TG. EGFRvIII-mediated transactivation of receptor tyrosine kinases in glioma: mechanism and therapeutic implications. Oncogene. 2015; 34:5277-87.

38. Soria JC, Cortes J, Massard C, Armand JP, De Andreis D, Ropert S, Lopez E, Catteau A, James J, Marier JF, Beliveau M, Martell RE, Baselga J. Phase I safety, pharmacokinetic and pharmacodynamic trial of BMS-599626 (AC480), an oral pan-HER receptor tyrosine kinase inhibitor, in patients with advanced solid tumors. Ann Oncol. 2012; 23:463-71.

39. Torres MA, Raju U, Molkentine D, Riesterer O, Milas L, Ang KK. AC480, formerly BMS-599626, a pan Her inhibitor, enhances radiosensitivity and radioresponse of head and neck squamous cell carcinoma cells in vitro and in vivo. Invest New Drugs. 2011; 29:554-61. 
40. Ni J, Cozzi P, Hao J, Beretov J, Chang L, Duan W, Shigdar S, Delprado W, Graham P, Bucci J, Kearsley J, Li Y. Epithelial cell adhesion molecule (EpCAM) is associated with prostate cancer metastasis and chemo/radioresistance via the PI3K/Akt/mTOR signaling pathway. Int J Biochem Cell Biol. 2013; 45:2736-48.

41. Chang L, Graham PH, Hao J, Ni J, Bucci J, Cozzi PJ, Kearsley JH, Li Y. Acquisition of epithelial-mesenchymal transition and cancer stem cell phenotypes is associated with activation of the PI3K/Akt/mTOR pathway in prostate cancer radioresistance. Cell Death Dis. 2013; 4:e875.

42. Gupta AK, McKenna WG, Weber CN, Feldman MD, Goldsmith JD, Mick R, Machtay M, Rosenthal DI, Bakanauskas VJ, Cerniglia GJ, Bernhard EJ, Weber RS, Muschel RJ. Local recurrence in head and neck cancer: relationship to radiation resistance and signal transduction. Clin Cancer Res. 2002; 8:885-92.

43. Blackhall FH, Pintilie M, Michael M, Leighl N, Feld R, Tsao MS, Shepherd FA. Expression and prognostic significance of kit, protein kinase $\mathrm{B}$, and mitogen-activated protein kinase in patients with small cell lung cancer. Clin Cancer Res. 2003; 9:2241-7.

44. Choe G, Horvath S, Cloughesy TF, Crosby K, Seligson D, Palotie A, Inge L, Smith BL, Sawyers CL, Mischel PS. Analysis of the phosphatidylinositol 3'-kinase signaling pathway in glioblastoma patients in vivo. Cancer Res. 2003; 63:2742-6.

45. Schmidt-Ullrich RK, Contessa JN, Lammering G, Amorino $\mathrm{G}$, Lin PS. ERBB receptor tyrosine kinases and cellular radiation responses. Oncogene. 2003; 22:5855-65.
46. Lammering G, Hewit TH, Valerie K, Lin PS, Contessa JN, Schmidt-Ullrich RK. Anti-erbB receptor strategy as a gene therapeutic intervention to improve radiotherapy in malignant human tumours. Int J Radiat Biol. 2003; 79:561-8.

47. Gurtner K, Ebert N, Pfitzmann D, Eicheler W, Zips D, Baumann M, Krause M. Effect of combined irradiation and EGFR/Erb-B inhibition with BIBW 2992 on proliferation and tumour cure in cell lines and xenografts. Radiat Oncol. 2014; 9:261.

48. Wong TW, Lee FY, Yu C, Luo FR, Oppenheimer S, Zhang H, Smykla RA, Mastalerz H, Fink BE, Hunt JT, Gavai AV, Vite GD. Preclinical antitumor activity of BMS-599626, a pan-HER kinase inhibitor that inhibits HER1/HER2 homodimer and heterodimer signaling. Clin Cancer Res. 2006; 12:6186-93.

49. Shi J, Yao D, Liu W, Wang N, Lv H, Zhang G, Ji M, Xu L, He N, Shi B, Hou P. Highly frequent PIK3CA amplification is associated with poor prognosis in gastric cancer. BMC Cancer. 2012; 12:50.

50. Engelman JA, Zejnullahu K, Mitsudomi T, Song Y, Hyland C, Park JO, Lindeman N, Gale CM, Zhao X, Christensen J, Kosaka T, Holmes AJ, Rogers AM, et al. MET amplification leads to gefitinib resistance in lung cancer by activating ERBB3 signaling. Science. 2007; 316:1039-43.

51. Hou P, Liu D, Shan Y, Hu S, Studeman K, Condouris S, Wang Y, Trink A, EI-Naggar AK, Tallini G, Vasko V, Xing M. Genetic alterations and their relationship in the phosphatidylinositol 3-kinase/Akt pathway in thyroid cancer. Clin Cancer Res. 2007; 13:1161-70. 